Research article

urn:lsid:zoobank.org:pub:D3B2953A-7727-4FA6-BADA-A74AEA6DF00B

\title{
Description of one new genus and four new species of mynoglenine spiders from Africa (Araneae: Linyphiidae: Mynogleninae)
}

\author{
Holger FRICK ${ }^{1, *} \&$ Nikolaj SCHARFF ${ }^{2}$ \\ ${ }^{1}$ Natural History Museum Aargau, Feerstrasse 17, CH - 5001 Aarau, Switzerland. \\ ${ }^{2}$ Natural History Museum of Denmark and Center for Macroecology, Evolution and Climate, \\ University of Copenhagen, Universitetsparken 15, DK-2100 Copenhagen, Denmark. \\ *Corresponding author: holger.frick@gmx.li \\ ${ }^{2}$ Email: nscharff@snm.ku.dk \\ ${ }^{1}$ urn:1sid:zoobank.org:author:4802D87A-A110-4A97-8C19-F5293EB3E5B2 \\ ${ }^{2}$ urn:1sid:zoobank.org:author:F84D2235-66D2-460C-820D-80024068759D
}

\begin{abstract}
The genus Camafroneta gen. nov. is established to accomodate Camafroneta oku gen. et sp. nov., a new species of mynoglenine spider from Cameroon, West Africa, with unusual complex male genitalia. Phylogenetic analyses suggest that the new species does not belong to a known genus of mynoglenine spiders. Another three new species of Afroneta Holm, 1968 from East Africa are described: Afroneta flavescens sp. nov., Afroneta serrata sp. nov. and Afroneta sarahae sp. nov. We also describe the missing sex $(\circlearrowleft)$ of Afroneta elgonensis Merrett, 2004.
\end{abstract}

Keywords. Afromontane, Afroalpine, taxonomy, systematics.

Frick H. \& Scharff N. 2018. Description of one new genus and four new species of mynoglenine spiders from Africa (Araneae: Linyphiidae: Mynogleninae). European Journal of Taxonomy 415: 1-27.

https://doi.org/10.5852/ejt.2018.415

\section{Introduction}

Little was known about spiders belonging to the subfamily Mynogleninae Lehtinen, 1967 until the faunas of New Zealand (Blest 1979) and Africa (Holm 1968; Merrett \& Russel-Smith 1996; Merrett 2004) were described. The mynoglenine fauna of New Zealand was thoroughly investigated by Blest (1979), Blest \& Vink $(2002,2003)$ and most of the African taxa were collected by Holm in 1948 in Kenya and Uganda, by Lejeune in 1974 in D.R. Congo and by Russell-Smith in the mid 1980s in Ethiopia.

Recently, a phylogeny of mynoglenine taxa was published (Frick \& Scharff 2014). The African taxa emerged paraphyletic with respect to only one genus Afromynoglenes Merrett \& Russel-Smith, 1996 (endemic to Ethiopia). All other African genera were monophyletic. Their interrelationships were weakly supported in this morphology-only based phylogeny, due to the relatively simple palpal conformations of the males, offering a lot less characters than the New Zealand taxa. 
Among the specimens examined for the phylogeny, Frick \& Scharff (2014) also studied samples from A. Holm's collection (stored at Uppsala), including some undescribed taxa. In this paper, we describe two new species that Holm had already mentioned in an unfinished manuscript discovered after his death in 1989. We also describe a new species that N. Scharff collected with colleagues in Cameroon in 1992 and the unknown male of Afroneta elgonensis Merrett, 2004.

\section{Material and methods}

Specimens were examined and illustrated using a Leica M205A stereo microscope equipped with a camera lucida and a Leica DFC 450C camera controlled by the program LAS V4.8. Single images were combined with Helicon Focus (v. 5.3; www.heliconsoft.com) software and Zerene Stacker (v. 1.04; www.zerenesystems.com) software to increase depth of field. Left structures (palps, legs etc.) are depicted unless otherwise stated. Drawings were made with soft pencils and a camera lucida. The vulvae were cleared with Hoyer's solvent (Kraus 1984) or methyl salicylate (Holm 1979). Holm's original labels in the specimen vials do not include georeferences, but these are given in Holm (1962). We added this information to the sections 'Material examined'. All measurements are in $\mathrm{mm}$.

Due to the exceptional characters found in Camafroneta oku gen. et sp. nov. (see below for details), the morphology of this species was scored and added to the phylogenetic matrix presented by Frick \& Scharff (2014) and subsequently analysed to find its position within Mynogleninae. See section "Phylogenetic position" under the description of Camafroneta oku gen. et sp. nov. for results and discussion.

\section{Abbreviations}

Following Frick \& Scharff (2014):

$\mathrm{ALE}=$ anterior lateral eyes

$\mathrm{AME}=$ anterior median eyes

$\mathrm{CD}=$ copulatory duct

$\mathrm{CO}=$ copulatory opening

$\mathrm{DP}=$ dorsal plate

DPS $=$ dorsal plate scape

$\mathrm{E} \quad=$ embolus

$\mathrm{FD}=$ fertilisation duct

$\mathrm{EM}=$ embolic membrane

$\mathrm{PC}=$ paracymbium

PS $=$ pedicel sternite

$\mathrm{R} \quad=$ radix

$\mathrm{S}=$ spermatheca

SPT = suprategulum

ST $=$ subtegulum

$\mathrm{SU}=$ sulcus

$\mathrm{T}=$ tegulum

$\mathrm{TB}=$ trichobothrium

$\mathrm{Tm} \mathrm{I}=$ relative position of trichobothrium on metatarsus I

$\mathrm{TMP}=$ tegular mynoglenine process

TRT = tibial retrolateral trichobothrium

$\mathrm{TPT}=$ tibial prolateral trichobothrium

$\mathrm{VP}=$ ventral plate

Institutional abbreviations appear in the Acknowledgements. 


\title{
Results
}

\author{
Class Arachnida Cuvier, 1812 \\ Order Araneae Clerck, 1757 \\ Family Linyphiidae Blackwall, 1859 \\ Subfamily Mynogleninae Lehtinen, 1967 \\ Camafroneta gen. nov. \\ urn:1sid:zoobank.org:act:A9911BE3-8F58-4BBB-BC5C-7116B2ECA337
}

\section{Type species}

Camafroneta oku gen. et sp. nov. by monotypy and present designation.

\section{Diagnosis}

Typical mynoglenine spiders with faint subocular sulci below ALE. With unusual genitalia and three instead of one trichobothrium on metatarsus I, which is unique within Linyphiidae. See section below for a description of the only known species in this genus.

\section{Etymology}

The name Camafroneta is an arbitrary combination of the abbreviation 'Cam' for the country Cameroon and the existing genus name Afroneta Holm, 1968. The gender of the name should be considered feminine. We follow the tradition within the subfamily Mynogleninae of including the name Afroneta in the new genus name.

\section{Remarks}

The phylogenetic analysis placed this species as sister to Laminafroneta Merrett, 2004 (see discussion of phylogeny under description of Camafroneta oku gen. et sp. nov.).

Merrett (2004) diagnosed the genus Laminafroneta by the males having an embolic membrane (conductor) that partly encircles the embolus (Merrett 2004: fig. 86) and the females having a broad, triangular, partly sclerotised dorsal plate (Merrett 2004: figs 87-88). The males of Camafroneta gen. nov. share the partly encircled shape of the embolic membrane, but this is also present in Afroneta tenuivulva Merrett, 2004 to a lesser extend and in most mynoglenines from New Zealand. The shape of the epigyne of Laminafroneta is very different from anything else known from mynoglenines, while that of Camafroneta gen. nov. resembles the one of Afroneta lobeliae Merrett, 2004 (Merrett 2004: fig. 28) and many other mynoglenines, especially from New Zealand. Including Camafroneta gen. nov. in Laminafroneta is, therefore, not justified.

Establishing a monotypic genus is unfortunate, because the genus will not add any grouping information until new species will be assigned to the genus. However, African mynoglenines are not well known and we probably only know a fraction of the existing taxa, especially from western Africa, where Camafroneta gen. nov. was found.

The most unique character present in Camafroneta gen. nov. are three trichobothria on metatarsus I (this was the case in all examined specimens of Camafroneta oku gen. et sp. nov.). The position of the trichobothrium on metatarsus I is one of the standard characters used to identify linyphiid spiders (see, e.g., Roberts 1987: tables A-D) and is routinely checked. The presence of more than one trichobothrium on metatarsus I is not known for any other linyphiid and is, therefore, unique to Camafroneta gen. nov. 
See more diagnostic details on the conformation of the male and female copulatory organs in the species diagnosis section below.

$$
\begin{aligned}
& \text { Camafroneta oku gen. et sp. nov. } \\
& \text { urn:1sid:zoobank.org:act:F50C5BCF-9115-4077-B335-AC9FAE5DB66E }
\end{aligned}
$$

Figs $1-3$

\section{Diagnosis}

The males are recognised by the moderately sclerotised embolic membrane that is enlarged with an ectal outwards fold (see Frick \& Scharff 2014: fig. 12B, EME) emerging on the prolateral side of the embolic membrane, encircling the distal half of the embolus. The retrolateral side of the embolic membrane has a fleshy appearance and is broadened distally before it narrows towards the tip. The size, degree of sclerotisation and complexity of the embolic membrane is unique within African mynoglenines.

The females can be diagnosed by their large dorsal plate scape that is almost as broad as the dorsal plate (Fig. 1C-D). It almost entirely extends over the posterior margin of the ventral plate, which is exceptional in mynoglenines.

\section{Etymology}

The species epiphet $o k u$ is derived from the type location close to Lake Oku near Mount Oku in western Cameroon. It is a name in apposition.

\section{Type material}

\section{Holotype}

CAMEROON: ${ }^{\wedge}$, Northwest Prov., Menchum Div., near Lake Oku, 06 ${ }^{\circ} 12^{\prime} \mathrm{N}, 10^{\circ} 27^{\prime} \mathrm{E}$, ca $2150 \mathrm{~m}$ a.s.1., 7-12 Feb. 1992, forest, C. Griswold, S. Larcher, N. Scharff and C. Wanzie leg. (ZMUC00046889).

\footnotetext{
Allotype

CAMEROON: + , same data as for holotype, epigyne separate (ZMUC00046889).

Other material examined $(9 \hat{\jmath} \widehat{\partial}, 33 \stackrel{+}{\phi})$

CAMEROON: 1 , together with holotype (ZMUC00046889); 1 , same locality and collecting date, forest litter (ZMUC 00046893); 1 \&, same locality and collecting date, forest litter (ZMUC00046898); 3 우, same locality and collecting date, forest litter (ZMUC00046897); 1 , same locality and collecting date, forest litter (ZMUC00046892); $2 \hat{\jmath} \widehat{\partial}, 8$ q $q$, same locality and collecting date, forest litter (ZMUC00046901); 1 § , 6 + $ᄋ$, same locality and collecting date, forest (ZMUC00046900); 1 , same locality and collecting date, forest, pitfall traps (ZMUC00046899); 1 , , same locality and collecting date, forest litter (ZMUC00046891); 1 ô, 2 우, same locality and collecting date, forest (ZMUC00046895); 1 §, 2 우우, same locality and collecting date, forest litter (ZMUC00046896); $2 \hat{\jmath} \widehat{\partial}, 3$ 우, same locality and collecting date, forest litter (ZMUC00046894); 2 우, same locality and collecting date, forest, pitfall traps (ZMUC00046890); $2 \hat{\jmath} \hat{\partial}, 1$ क , same locality and collecting date, forest litter (ZMUC00046888).
}

\section{Description}

Holotype (holotype, ZMUC00046889)

Size. Total length 2.98. Cephalothorax 1.44 long, 0.98 wide. Sternum 0.85 long ( 0.76 without labium), 0.65 wide. Abdomen 1.70 long, 0.96 wide. AME diameter 0.04. Femur I 1.31 long, 0.91 times as long as cephalothorax. 
Colour (preserved specimen, Fig. 3B, E-F). Cephalothorax and chelicerae yellowish brown mottled with grey. Legs and pedipalps yellowish white, without annulations. Black rings around eyes. Abdomen light grey, with white markings.

Body. Sternum shield-shaped with labium fused to sternum and long narrow extension of sternum between coxae IV (merged to carapace at the end) (Fig. 3C, G). Cephalothorax without setae. Fovea present, elongated, faint and shallow. Ocular area with several short thin setae between eyes. Clypeus height 5.5 times AME diameter. Subocular sulci present below ALE, long and wide, not clearly demarcated (Fig. 3B, lines).
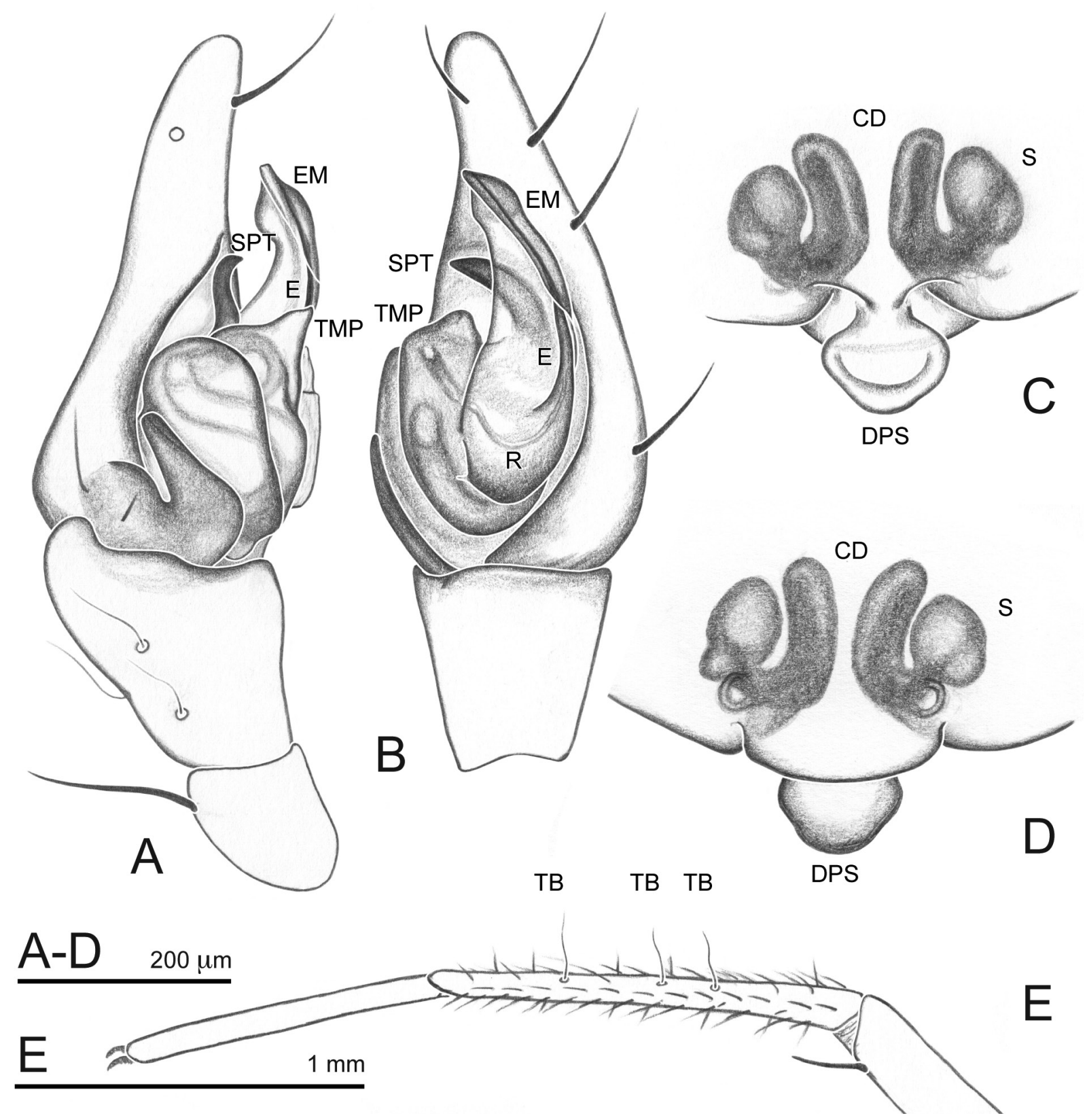

Fig. 1. Camafroneta oku gen. et sp. nov. A-B. Holotype, đ (ZMUC00046889). A. Palp, retrolateral. B. Prolateral. C-D. Allotype, q (ZMUC00046889). C. Epigyne, ventral. D. Vulva, dorsal. E. $q$ (ZMUC00046901) metatarsus 1, retrolateral. 
Chelicerae. With 3 large widely spaced prolateral teeth (middle tooth largest) (Fig. 3B). With faint stridulating ridges. Three small closely spaced retrolateral denticles, positioned between the two first prolateral teeth.

LEGS. All femora with one short stout setae dorsally. Leg formula 1243 (legs 1, 2 of 4 almost same length). Tibial spinal formula 2222. Metatarsus I with 3 dorsal trichobothria.

Pedipalp (Figs 1A-B, 2A-D). Patella with long strong distal dorsal spine (Figs 1A, D, 2A). Tibia with two retrolateral and one prolateral trichobothrium (Fig. 1A). Cymbium with one distal ventral and three prolateral macrosetae. Paracymbium U-shaped, with large broad base and two basal hairs (Figs 1A, 2A).

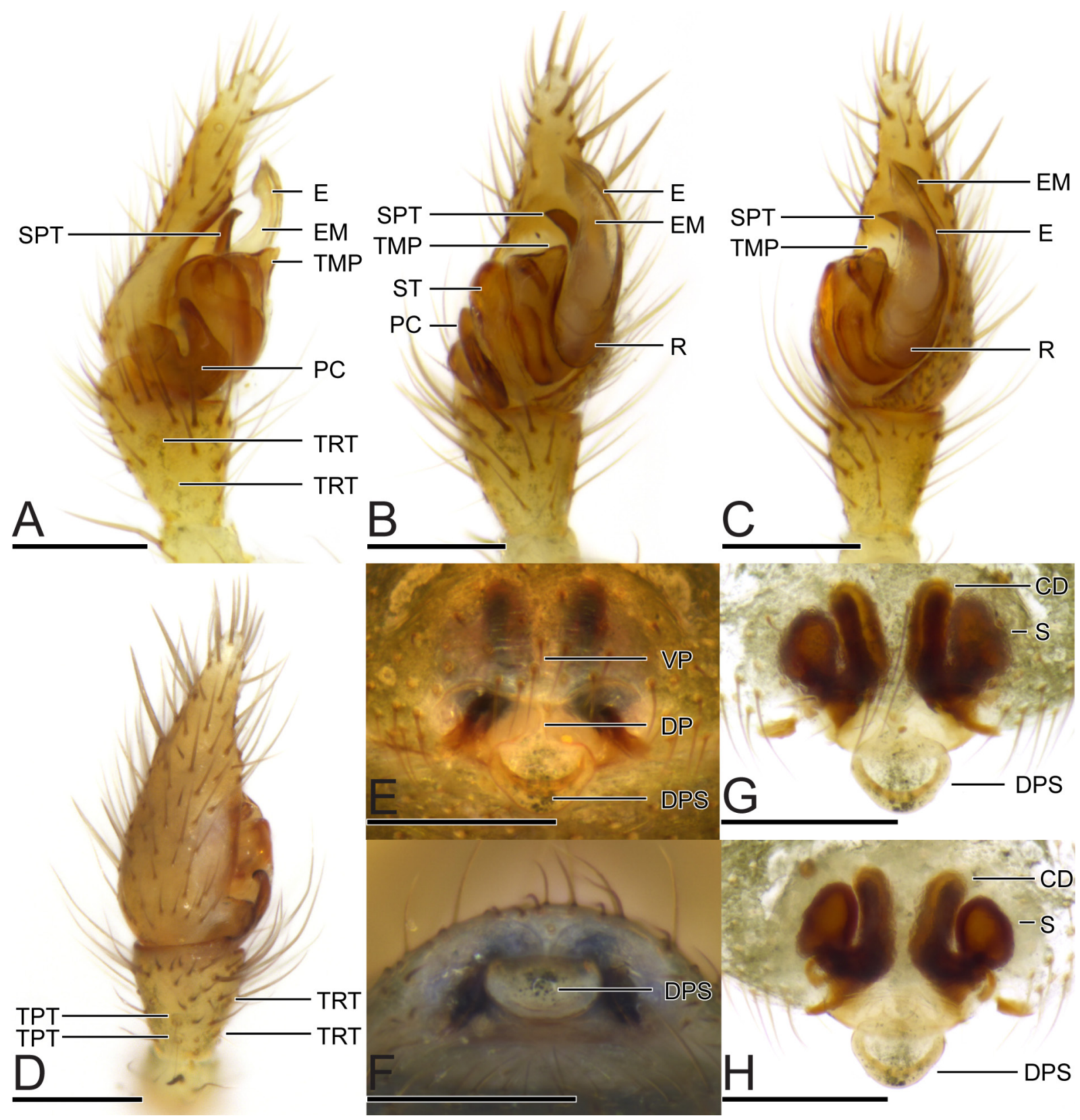

Fig. 2. Camafroneta oku gen. et sp. nov. A-D. Holotype, $\widehat{\jmath}$ (ZMUC00046889). A. Palp, retrolateral. B. Ventral. C. Prolateral. D. Dorsal. E-H. Allotype, $q$ (ZMUC00046889). E. Epigyne, ventral. F. Aboral. G. Cleared vulva, ventral. H. Dorsal. Scale bars: $200 \mu \mathrm{m}$. 
Protegulum elongated, triangular (Figs 1A, 2A). Suprategulum finger-like pointing retrolaterally. Radix drop-shaped with a tiny, in the light microscope almost invisible thorn on its retrolateral side (Fig. 1B). It resembles the radix retrolateral appendix described by Frick \& Scharff (2014) for Metamynoglenes Blest, 1979, but it is much smaller in Camafroneta gen. nov. Embolus long and thin embedded in the embolic membrane (Figs 1B, 2B-C). Embolic membrane moderately sclerotised and enlarged (compared to other African mynoglenines), exceeding the alveolus. Distal half peculiarly shaped with folds and seemingly fleshy sections.

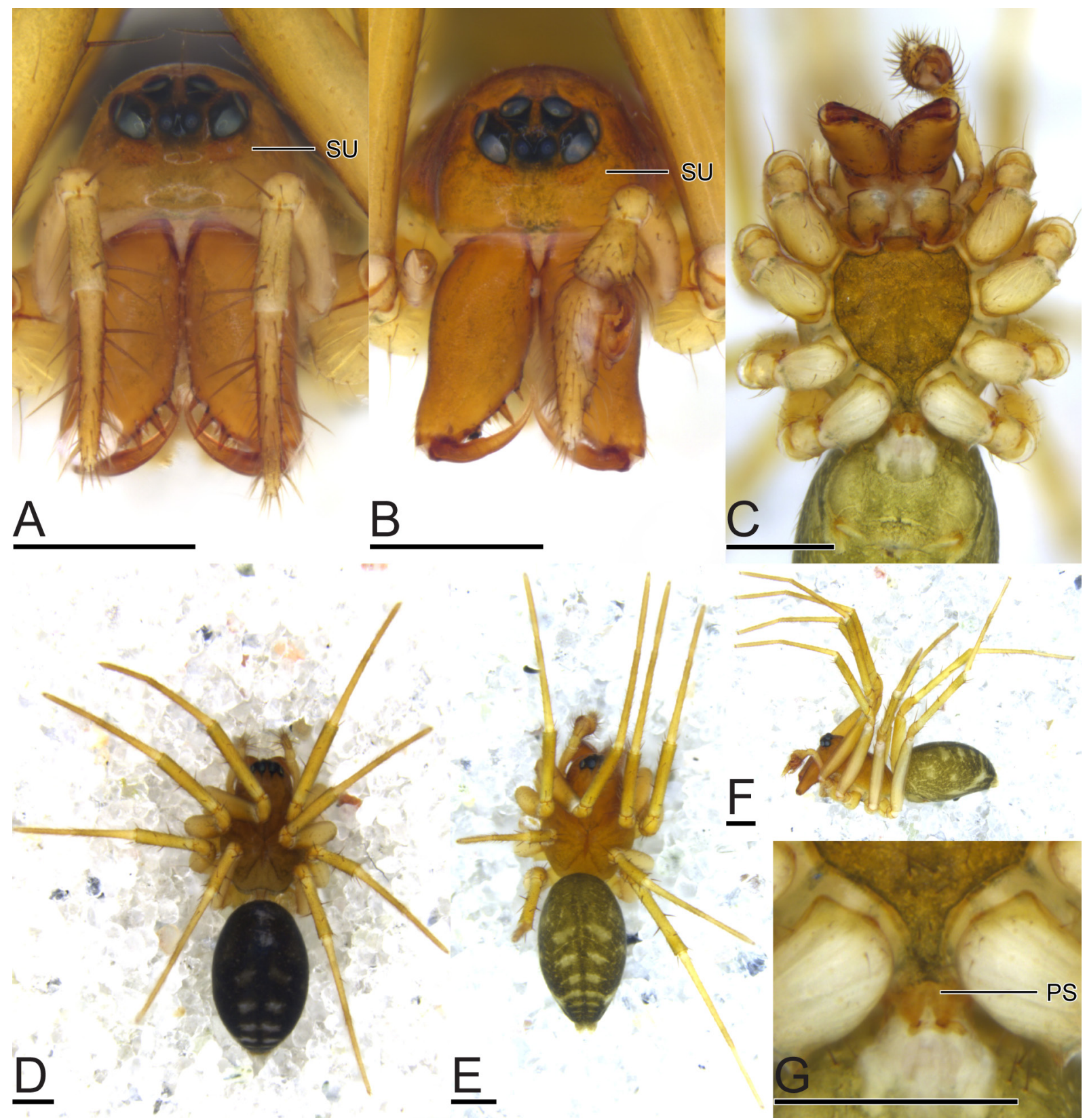

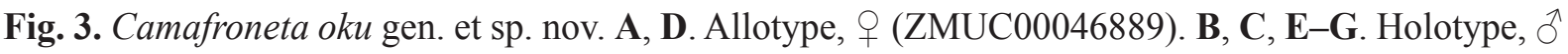
(ZMUC00046889). A. Habitus, frontal. B. Habitus, frontal. C. Sternum. D. Habitus, dorsal. E. Habitus, dorsal. F. Habitus, lateral. G. Petiolus, ventral. Scale bars: $500 \mu \mathrm{m}$. 
Female (allotype, ZMUC00046889)

SizE. Total length 3.22. Cephalothorax 1.43 long, 0.99 wide. Sternum 0.91 long ( 0.84 without labium), 0.66 wide, shield-shaped. Abdomen 1.69 long, 1.17 wide. AME diameter 0.04. Femur I 1.20 long, 1.19 times as long as cephalothorax.

Colour (preserved specimen). As holotype, but abdomen darker, greyish black (Fig. 3A, D).

Body. Similar to male. Clypeus height 5.75 times AME diameter. Subocular sulci present below ALE, long and wide, not clearly demarcated (Fig. 3A).

Chelicera. Cheliceral teeth and stridulation file as in male (Fig. 3A).

Legs. Leg formula 1243. Metatarsus with 3 trichobothria (Fig. 1E). Spination of legs as in male.

Epigynum And vulva (Figs 1C-D, 2F-H). The epigyne has a large dorsal plate scape. It is almost as broad as the dorsal plate in ventral view (Fig. 1C), extending the posterior margin of the ventral plate almost entirely (Fig. 1C-D). The copulatory ducts are simple, curved and extend beyond the round receptaculum anteriorly.

\section{Variation}

Males $(\mathrm{n}=5$ ): total length 2.79-3.06, cephalothorax length 1.28-1.51, cephalothorax width $0.87-1.05$, femur I length 1.20-1.41. Females $(\mathrm{n}=5)$ ): total length 2.98-3.90, cephalothorax length 1.36-1.60, cephalothorax width $0.97-1.13$, femur I length 1.13-1.41.

\section{Distribution}

Only known from the type locality, forests around Lake Oku $\left(06^{\circ} 12^{\prime} \mathrm{N}, 10^{\circ} 27^{\prime} \mathrm{E}\right)$, Cameroon, at an altitude of $2150 \mathrm{~m}$.

\section{Life history}

Little is known about the biology of this species. Specimens have been collected in forest litter and pitfall traps in montane rain forest.

\section{Phylogenetic position}

Camafroneta oku gen. et sp. nov. scored as follows in the phylogenetic analysis. The exact same methods (the same batch files in TNT) were used to run the analyses as described in Frick \& Scharff (2014): $100000110100000000211000101200000011000110100-11010001100110111101101101000$ $1001000000110101100010200011011110011011000010000100---00100110110112200110$ 1001000220010210111101211111001210100101.

The analysis resulted in three most parsimonious trees of 893 steps (160 hits out of 1000). The three trees only differ in changes within Haplinis Simon, 1894 and are, apart from the addition of Camafroneta oku gen. et sp. nov., equal to the three trees found in Frick \& Scharff (2014).

Camafroneta oku gen. et sp. nov. is a sister to the highly supported genus Laminafroneta (Fig. 14). Together they are sister to Afroneta Holm, 1968. However, both relationships are not well supported (Bremer $=1$; Jackknife $<50 \%$ ) and therefore likely to change. Since Camafroneta oku gen. et sp. nov. did not emerge within a supported genus and morphologically differs highly from both presumably closely related genera Laminafroneta and Afroneta, a new monotypic genus is described. Erecting a new monotypic genus can also be justified by the fact, that the African mynoglenine fauna is highly undersampled. It is therefore likely, that more species of the genus will be discovered once the 
mountainous areas of central to western Africa are more thoroughly investigated. It could be argued, that as sister taxa to Laminafroneta, we should place it within Laminafroneta, but this would leave Laminafroneta hard to define morphologically. Camafroneta gen. nov. is morphologically very different (see remarks).

Genus Afroneta Holm, 1968

Afroneta flavescens sp. nov. urn:1sid:zoobank.org:act:920C61D3-CD79-464D-8BE3-853A17227ED7

Figs $4-5,6 \mathrm{~A}-\mathrm{C}$

\section{Diagnosis}

Males can be recognised by the combination of a simple radical division and the form of the paracymbium (Fig. 4A-B). The females have a round, but separated receptaculum (Fig. 4C). The copulatory duct
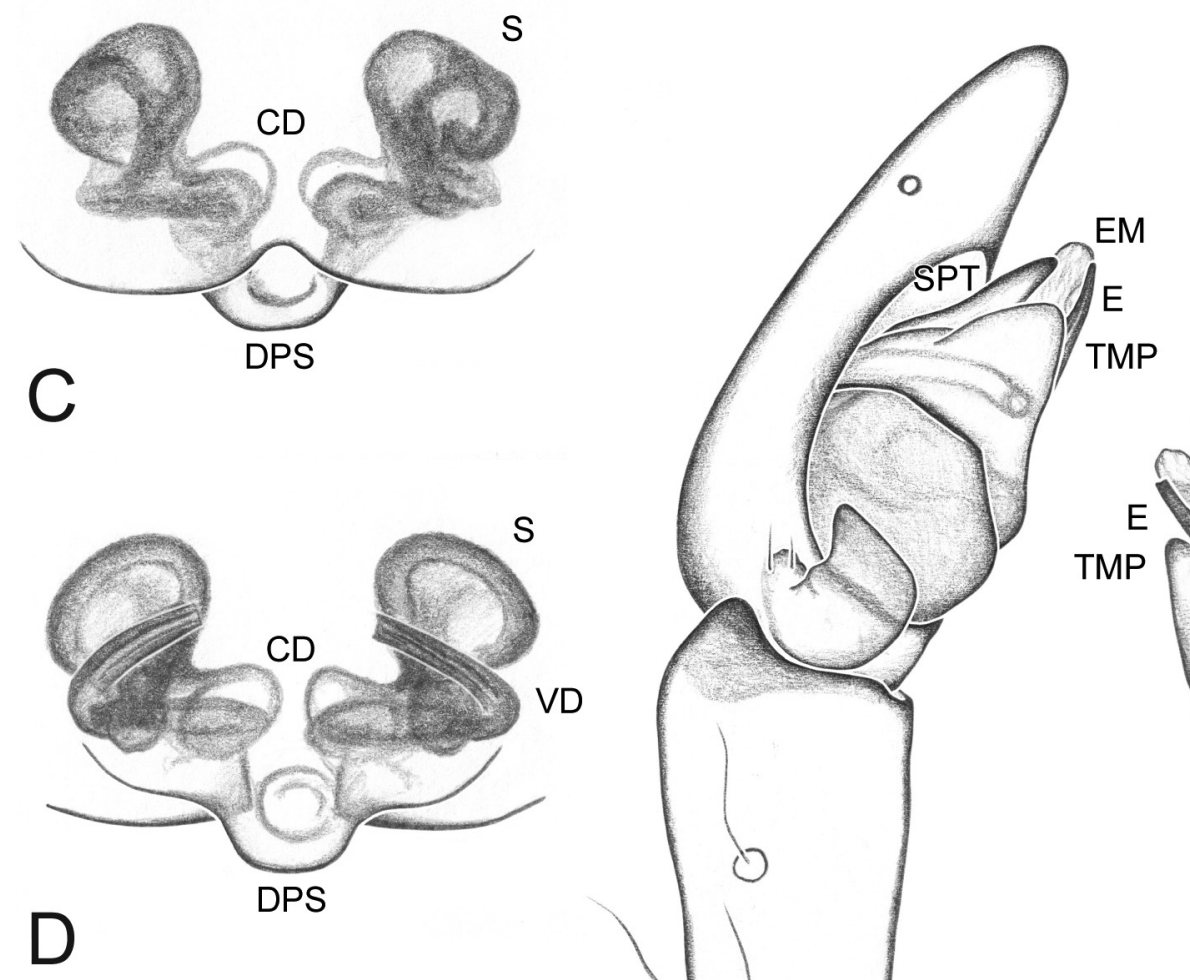
is very short facing laterally directly from the copulatory opening into the receptaculum (Fig. 4D). The whole body of both sexes is uniformly yellow (Figs 5A-D, 6A-C). Both sexes resemble Afroneta bamilekei Bosmans, 1988, but the spination is very different, e.g., spine formula 0000 in A. bamilekei (Bosmans 1988; Merrett 2004), 2222 in Afroneta flavescens sp. nov.

\section{Etymology}

The species epithet flavescens refers to the yellowish (Latin 'flavus') colour of the specimens. Holm suggested this name for these specimens in his unfinished manuscript, but never published the data (Wallin 1990).

\section{Type material}

\section{Holotype}

KENYA: ${ }^{\lambda}$, Mount Elgon, $3200 \mathrm{~m}$ a.s.1., $01^{\circ} 10^{\prime} 00^{\prime \prime} \mathrm{N}, 34^{\circ} 40^{\prime} 00^{\prime \prime} \mathrm{E}$, "sålln., mossa på trädstammar" (sifted moss on trees), 9 Mar. 1938, Å. Holm leg. and det., collection Holm UZM No. 137 (UPSZMC 67563).

\section{Allotype}

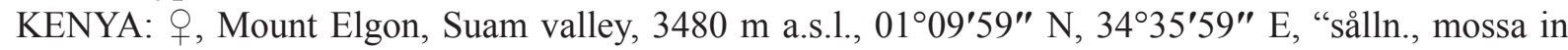
Alckemilla-hed" (sifted moss in Alckemilla-heather), 17 May 1948, A. Holm leg. and det., collection Holm UZM No. 158 (UPSZMC 67564).

\section{Description}

Male (holotype, UPSZMC 67563)

SizE. Total length 2.70. Cephalothorax 1.35 long, 0.95 wide. Sternum 0.89 long ( 0.77 without labium), 0.67 wide. Abdomen 1.41 long, 0.78 wide. AME diameter 0.03. Femur I 1.40 long, 1.04 times as long as cephalothorax.

Colour (preserved specimen). Cephalothorax yellowish. Chelicerae, sternum, pedipalps, legs and abdomen yellowish (Fig. 6C). The colour seen in the female (Fig. 6A) also most resembles the true body colour of the male. Black rings around eyes, just like the females (Fig. 6A).

Body. Cephalothorax with many short setae. Fovea present, elongated, darker brown, faint/shallow (Fig. 6C). Ocular area with several short thin setae between eyes. Clypeus with strong setae below AME. Clypeus height 6.3 times AME diameter. Subocular sulci (SU) present below AME, long and wide, but not clearly demarcated as in the females (Fig. 6A). Sternum shield-shaped with labium fused to sternum and short narrow extension of sternum between coxae IV (merged to carapace at the end).

Chelicerae. With 3 large widely spaced prolateral teeth. Stridulating files not visible on chelicerae. Three small widely spaced retrolateral denticles, positioned between the two first prolateral teeth.

Legs. All femora with two short stout setae dorsally. Leg formula 1243 (legs 1,2 of 4 almost same length). Trichobothrium metatarsus I $=0.59$, very hard to see. Tibial spinal formula 2222 .

Pedipalp (Figs 4A-B, 5A-D). Patella with long strong distal dorsal spine (Fig. 4A). Tibia about as long as cymbium, with two retrolateral and one prolateral trichobothrium (Figs 4A, 5D). Cymbium with two prolateral macrosetae. Paracymbium curved, with two basal macrosetae (Fig. 4A). Tegular mynoglenine process broad triangular, facing distally (Fig. 4A-B). Suprategulum almost straight, finger-like (Fig. 4A). Radix drop-like with small straight, robust embolus. According to Merrett (2004), this is also present in Afroneta bamilekei Bosmans, 1988. Embolic membrane small, only slightly longer than embolus, exceeding the cymbium marginally (Fig. 4B). 
Female (allotype, UPSZMC 67564)

SizE. Total length 3.25. Cephalothorax 1.53 long, 0.99 wide. Sternum 0.86 long ( 0.79 without labium), 0.66 wide. Abdomen 1.86 long, 1.08 wide. AME diameter 0.04. Femur I 1.48, long, 0.97 times as long as cephalothorax.

Colour (preserved specimen, Fig. 6B). As male holotype. The difference in colour in Figures 6B and $\mathrm{C}$ is a technical relict from the different backgrounds. The yellow in Fig. 6A is closest to the real body colour.

BoDy. Sternum shield-shaped, like male. Clypeus height 5.75 times AME diameter.

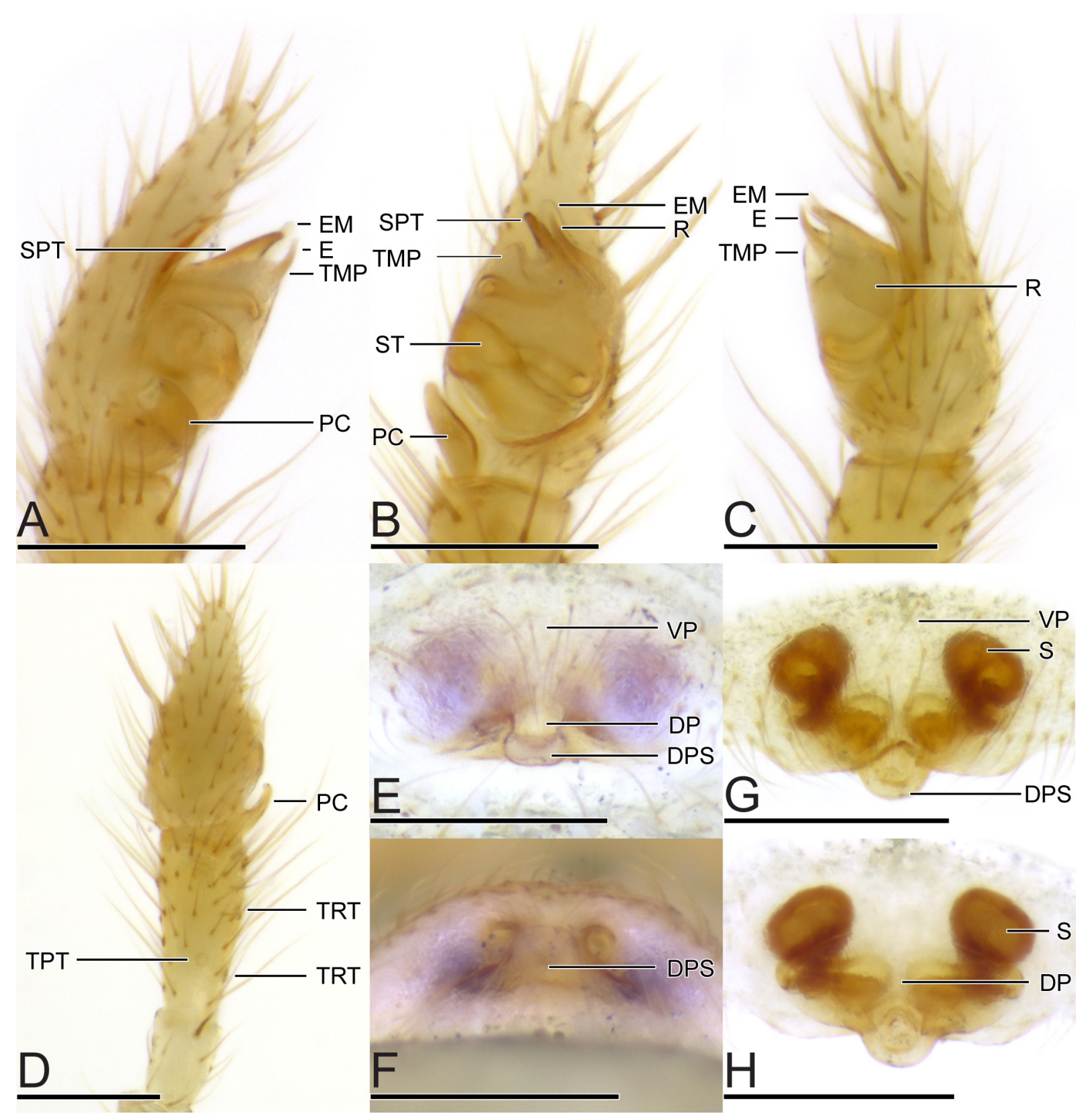

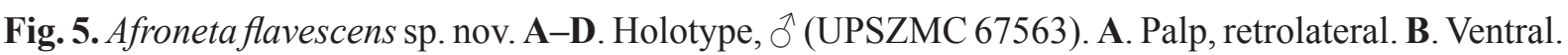
C. Prolateral. D. Dorsal. E-H. Allotype, $q$ (UPSZMC 67564). E. Epigyne, ventral. F. Aboral. G. Cleared vulva, ventral. H. Cleared vulva, dorsal. Scale bars: $200 \mu \mathrm{m}$. 
Chelicerae. Cheliceral teeth (Fig. 6A) and stridulation file as in male. Spination of legs as in male. Leg formula 1243. Trichobothrium metatarsus $\mathrm{I}=0.53$, very hard to see.

EpigYnum. The females have a round, centrally separated receptaculum (Figs 4C, 5G-H). The dorsal plate scape is well developed (Fig. 5E-F). The copulatory duct is very short facing laterally directly from the copulatory opening to the receptaculum and lacking an anteriorly facing copulatory duct (Figs 4C-D, 5G-H).

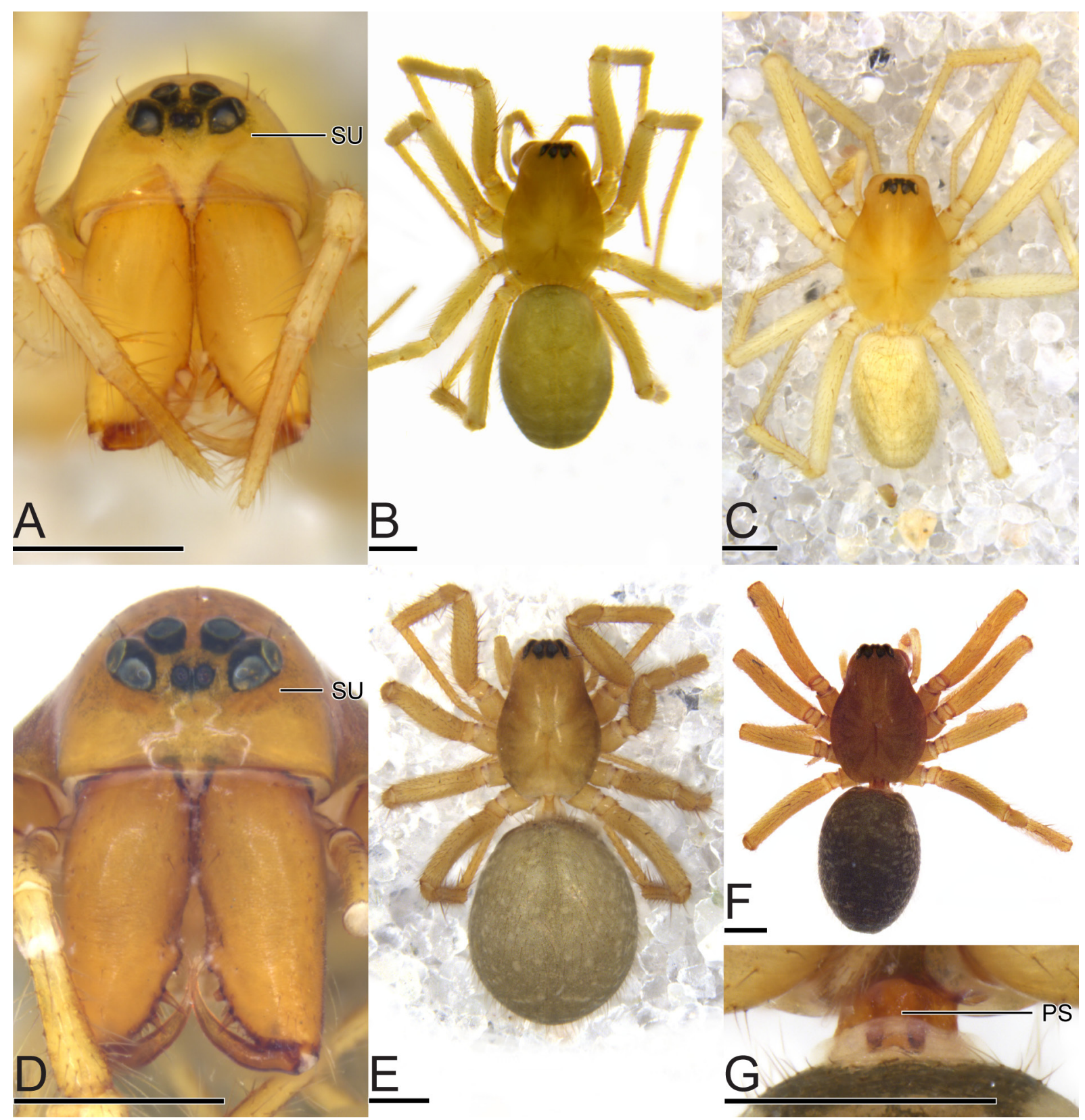

Fig. 6. Afroneta flavescens sp. nov. A-B. Allotype, $q$ (UPSZMC 67564). A. Habitus, frontal. B. Dorsal. C. Holotype, ô (UPSZMC 67563), habitus, dorsal. - D-G. Afroneta elgonensis Merrett, 2004.

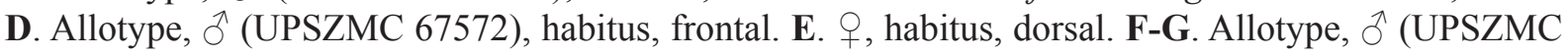
67572). F. Habitus, dorsal. G. Petiolus, ventral. Scale bars: $500 \mu \mathrm{m}$. 


\section{Distribution}

Only known from Mount Elgon over 3200 m a.s.1.

\section{Life history}

Little is known about the biology of this species. Specimens have been collected from moss on trees and in heather above $3200 \mathrm{~m}$.

\section{Comments}

This species was originally recognized by Holm, who also suggested what specimen to use as holotype, but he never published the new species and a draft manuscript has not been found. The specimens of the new species are already listed in an unpublished report from the Zoological Museum, Uppsala University (Wallin 1990) as Afroneta flavescens MS.

\section{Afroneta elgonensis Merrett, 2004 \\ Figs $6 \mathrm{D}-\mathrm{G}, 7-8$}

Afroneta elgonensis Merrett, 2004: 4, figs 11-13.

\section{Diagnosis}

The male can be diagnosed by the very long palpal tibia. It is clearly longer than the cymbium. This is not the case in any other Afroneta with a short, robust and straight embolus.

\section{Type material}

\section{Allotype}

KENYA: 1 Јึ, Mount Elgon, eastern side, 2900 m a.s.1., 13-15 Jan. 1965, A. Holm leg., H. Frick det., collection Holm UZM No. 40 (UPSZMC 67572).

\section{Other material examined $(1 \hat{\jmath}, 4$ 우)}

KENYA: 1 , same data as for allotype; 2 q , Mount Elgon, E side, 3050 m a.s.1., 16 Jan. 1965, Å. Holm leg., H. Frick det., collection Holm UZM No. 80 (UPSZMC 67583); 1 §,, Mount Elgon, eastern side, "sålln., lövförne i Hagenia skog i dal" (sifted litter in Hagenia forest, in valley), $3200 \mathrm{~m}$ a.s.1., 9 May 1948, Å. Holm leg., H. Frick det., (originally listed by Holm as Afroneta longipalpis MS in the unpublished report from Uppsala), Collection Holm UZM No. 130 (UPSZMC 67558); 1 +, Mount Elgon, East of Koitoboss, "sålln., lövförna mln grästuvor" (sifted litter between grass tussocs), $3300 \mathrm{~m}$ a.s.1., 28 Mar. 1938, Å. Holm leg., H. Frick det. (originally listed by Holm as Afroneta longipalpis MS in the unpublished report from Uppsala), collection Holm UZM No. 174 (UPSZMC 67559).

\section{Description}

Male (allotype, UPSZMC 67572)

Size. Total length 3.17. Cephalothorax 1.47 long, 1.06 wide. Sternum 0.86 long ( 0.79 without labium), 0.73 wide. Abdomen 1.68 long, 1.21 wide. AME diameter 0.04. Femur I 1.32 long, 1.11 times as long as cephalothorax.

Colour (preserved specimens, Figs 6D, 7A-H). Cephalothorax, chelicerae, pedipalps and legs yellowish brown. Abdomen light to dark grey with small white dots. Black rings around eyes (Fig. 6D).

Body. Sternum shield-shaped with labium fused to sternum and long narrow extension of sternum between coxae IV (merged to carapace at the end). Cephalon with short setae. Fovea present, canoe- 
shaped, faint/shallow. Ocular area with several short thin setae between eyes. Clypeus height 5.25 times AME diameter. Subocular sulci present below ALE, long and wide, not clearly demarcated (Fig. 6D). Chelicerae with 3 large widely spaced prolateral teeth (Fig. 6D) and three small closely spaced retrolateral denticles. Chelicerae with stridulating file.

Legs. All femora with one short stout setae dorsally. Leg formula 1243 (legs 1,2 of 4 almost same length). Trichobothrium metatarsus I $=0.58$. Tibial spine formula 2222. As seen in the females, the males also lack metatarsal macrosetae and retrolateral tibial macrosetae. This is diagnostic according to Merrett (2004). However, Afroneta flavescens sp. nov. also lacks these macrosetae.

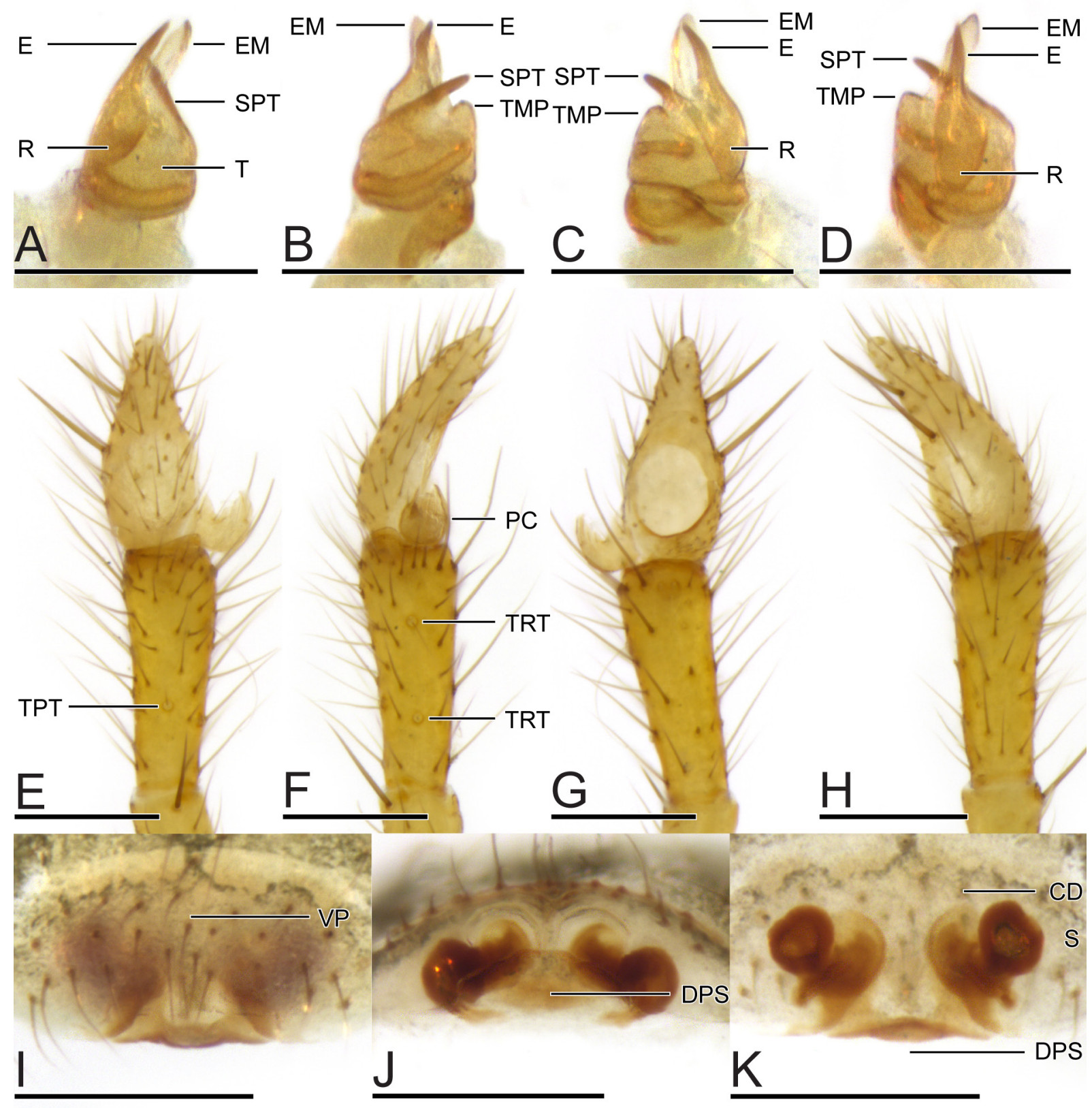

Fig. 7. Afroneta elgonensis Merrett, 2004. A-H.Allotype, $\widehat{\jmath}$ (UPSZMC 67572). A. Left bulbus (mirrored), dorsal. B. Retrolateral. C. Ventral. D. Prolateral. E. Left palp (mirrored), dorsal. F. Retrolateral. G. Ventral. H. Retrolateral. I-K. $\odot$ (UPSZMC 67572). I. Epigyne ventral. J. Aboral. K. Dorsal. Scale bars: $200 \mu \mathrm{m}$. 
Pedipalp (Figs 7A-H, 8A-D). Patella with long strong distal dorsal spine (Fig. 8D). Tibia with two retrolateral and one prolateral trichobothrium (Figs 7E-F, 8D). Cymbium with two prolateral macrosetae. Paracymbium U-shaped with two basal hairs (Figs 7E, 8D). Suprategulum straight, finger-like, pointing retrolaterally (Fig. 8B). Tegular mynoglenine process weakly developed (Fig. 8C), Radix drop-like, embolus robust and straight (Figs 7D, 8A). This type of embolus is very rare in Afroneta and otherwise only known from Afroneta flavescens sp. nov. and Afroneta bamilekei. The embolic membrane is simple, as large as the embolus.

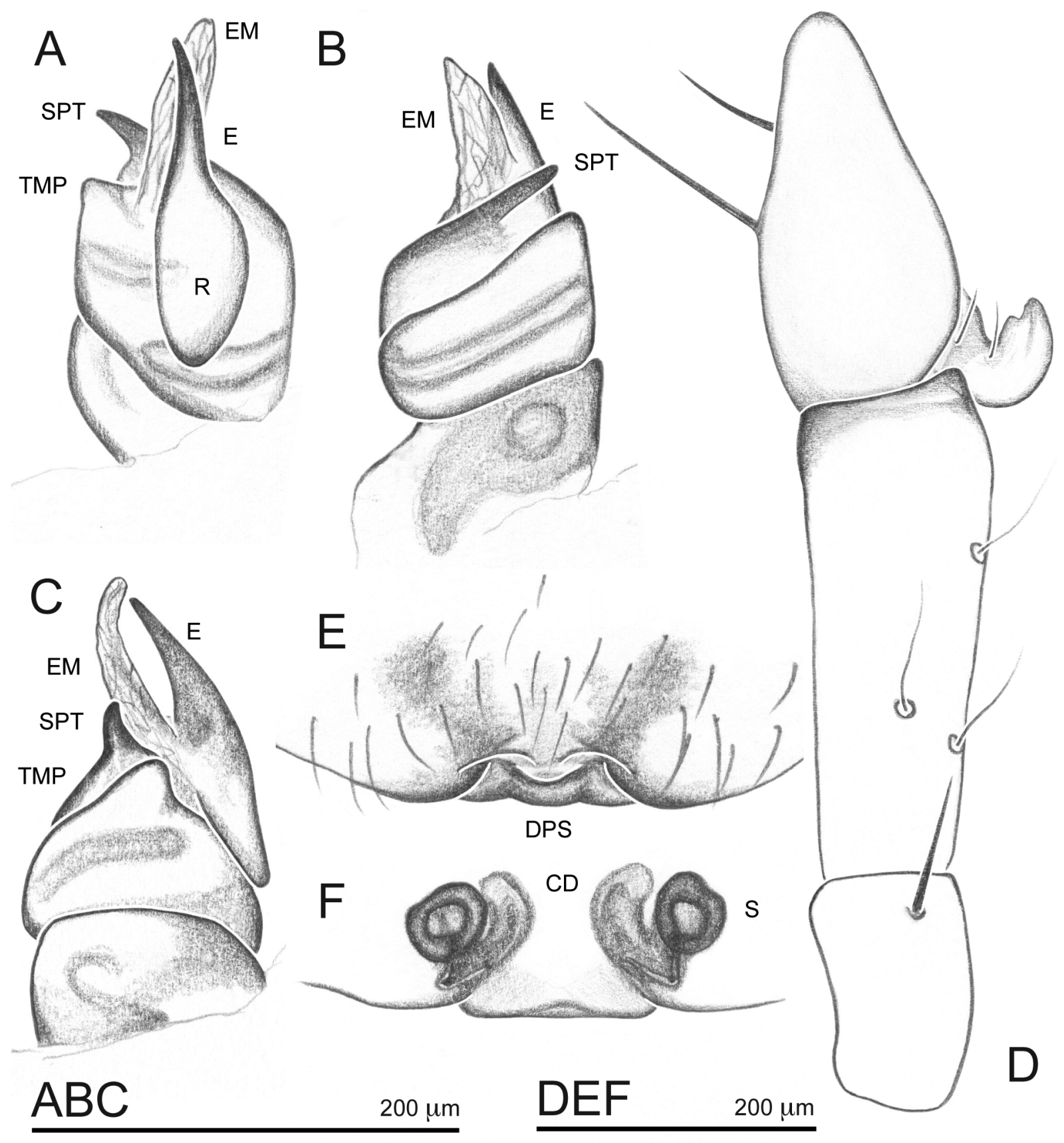

Fig. 8. Afroneta elgonensis Merrett, 2004. A-D. Allotype, ô (UPSZMC 67572). A. Bulbus, prolateral. B. Dorsal. C. Ventral. D. Palp, dorsal. E-F. ㅇ (UPSZMC 67572). E. Epigyne, ventral. F. Vulva, dorsal. 


\title{
Female
}

The female of this species was described by Merrett (2004) based on 11 specimens from Mount Elgon at $3100 \mathrm{~m}$ a.s.1. Holm's material was taken on Mount Elgon from 2900 to $3300 \mathrm{~m}$ a.s.1.; the epigyne and vulva (Figs 7I-K, 8E-F) match the drawings of Merrett (2004: figs 11, 13). Furthermore, Merrett (2004) mentions an unusual chaetotaxy that is diagnostic for the species. Afroneta elgonensis has no metatarsal spines or retrolateral tibial spines. This is also the case for the specimens in Holm's collection. Moreover, the male and the female have a relatively long palpal tibia.

\section{Distribution}

Only known from Mount Elgon, Kenya, at altitudes from 2900-3300 m a.s.1.

\section{Life history}

Little is known about the biology of this species. The few specimens recorded have all been taken from litter in montane forest or grasslands.

\author{
Afroneta serrata sp. nov. \\ urn:1sid:zoobank.org:act:43E22AFC-D784-4494-8F78-87E9657584D3
}

Figs 9-10, 11A-C

\section{Diagnosis}

In males, the presence of serrations on the ventral margin of the paracymbium is diagnostic. However, the shape of the serrations is variable (see Fig. 9A-B), ranging from many shallow fine denticles to a few deep strong teeth. The tegular mynoglenine process tapers towards the tip and is well set off from the tegulum (Figs 9A, 10A-B). Females have a small dorsal plate scape and copulatory ducts that exceed the receptacula anteriorly.

\section{Etymology}

The species epithet serrata refers to the serrated paracymbium of the males. The gender is feminine. This species was discovered by Holm, who also suggested the specimen to use as holotype, but the species was never published. The material of this species is listed in an unpublished catalogue from the Zoological Museum at the Uppsala University (Wallin 1990) as Afroneta serrata MS.

\section{Type material}

\section{Holotype}

KENYA: Ō, Mount Elgon, Koitobboss, Alpine belt, "Sålln., moss m.m. på marken" (sifted moss etc., on the ground), $1^{\circ} 08^{\prime} \mathrm{N}, 34^{\circ} 36^{\prime} \mathrm{E}, 4200 \mathrm{~m}$ a.s.1., 11 May 1948, $\AA$. Holm leg. and det., collection Holm UZM No. 142 (UPSZMC 67569).

\section{Allotype}

KENYA: $q$, same data as for holotype (UPSZMC 67569).

\section{Other material examined $(2 \hat{\jmath})$}

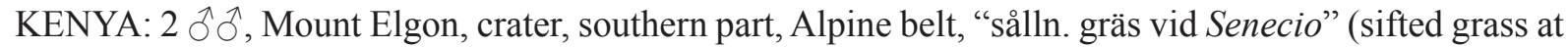
Senecio), $1^{\circ} 07^{\prime} \mathrm{N}, 34^{\circ} 34^{\prime}$ E, 3980 m a.s.1., 14 May 1948, Å. Holm leg. and det., collection Holm UZM No. 62/147 (UPSZMC 67570). 


\section{Description}

Male (holotype, UPSZMC 67569)

SizE. Total length 1.98. Cephalothorax 1.13 long, 0.81 wide. Sternum 0.71 long ( 0.60 without labium), 0.56 wide. Abdomen 1.08 long, 0.66 wide. AME diameter 0.04. Femur I 0.70 long, 1.01 times as long as cephalothorax.

Colour (preserved specimens, Fig. 11A, C). Cephalothorax and chelicerae brownish, sternum darker and with blackish-grey margin. Legs and pedipalps yellowish white, without annulations. Black rings
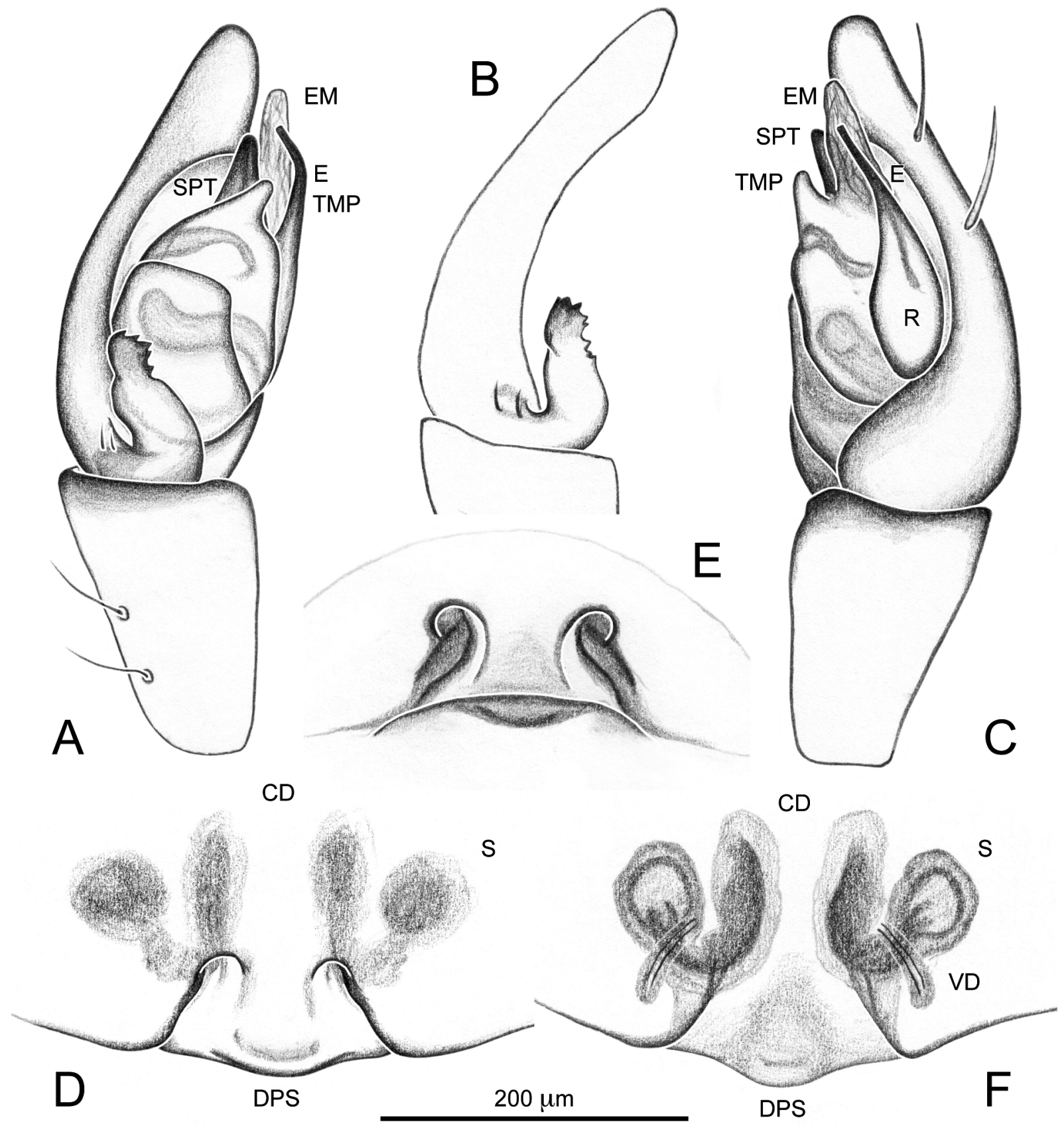

Fig. 9. Afroneta serrata sp. nov. A-C. Holotype, đ (UPSZMC 67569). A. Palp, retrolateral. B. Paracymbium, retrolateral. C. Prolateral. D-F. Allotype, $q$ (UPSZMC 67569). D. Epigyne, ventral. E. Aboral. F. Vulva, dorsal. 
around eyes (Fig. 11A). Abdomen grey, with white markings. Figure 11A illustrates old material (1948) stored in $75 \%$ ethanol.

Body. Cephalothorax with short pale setae in the midline. No fovea (Fig. 11C). Ocular area with several short thin setae between eyes. Clypeus height 4.6 times AME diameter. Subocular sulci present below ALE, clearly demarcated, longer than wide and narrow (Fig. 11A).

Chelicerae. With 3 large widely spaced prolateral teeth (Fig. 11A). No stridulating file. Three small closely spaced retrolateral denticles, positioned between the two first prolateral teeth.

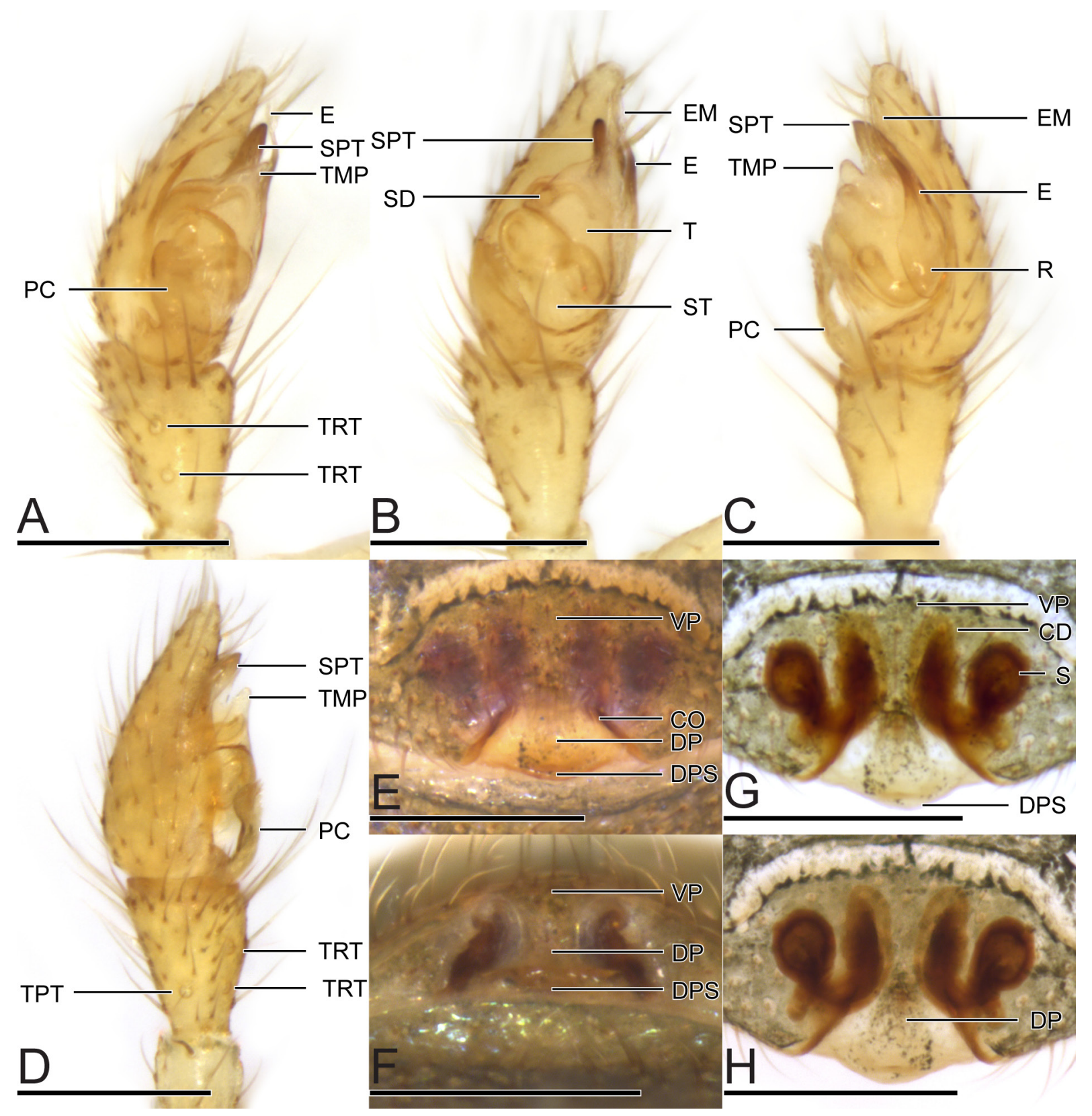

Fig. 10. Afroneta serrata sp. nov. A-D. ô (UPSZMC 67570). A. Palp, retrolateral. B. Ventral. C. Prolateral. D. Dorsal. E-H. Allotype, $q$ (UPSZMC 67569). E. Epigyne, ventral. F. Aboral. G. Cleared vulva, ventral. H. Dorsal. Scale bars: $200 \mu \mathrm{m}$. 
Legs. All femora with short thin setae dorsally and ventrally. Ventral setae several times longer than diameter of femora. Leg formula 1243. Trichobothrium metatarsus I = 0.49. Tibial spine formula 2222.

Pedipalp (Figs 9A-C, 10A-D, 11A). Patella with long strong macro setae (Fig. 10A). Tibia with two retrolateral and one prolateral trichobothrium (Figs 9A, 10D). Cymbium with two prolateral macrosetae (Fig. 9C). Paracymbium J-shaped, with unusual distal serrations on ventral margin (Fig. 9A-B). It bears two setae basally (Fig. 9A) and its distal part is well set off from the cymbium in dorsal view (Fig. 10D). Suprategulum narrow, triangular. Tegular mynoglenine process elongated, well set off from the tegulum
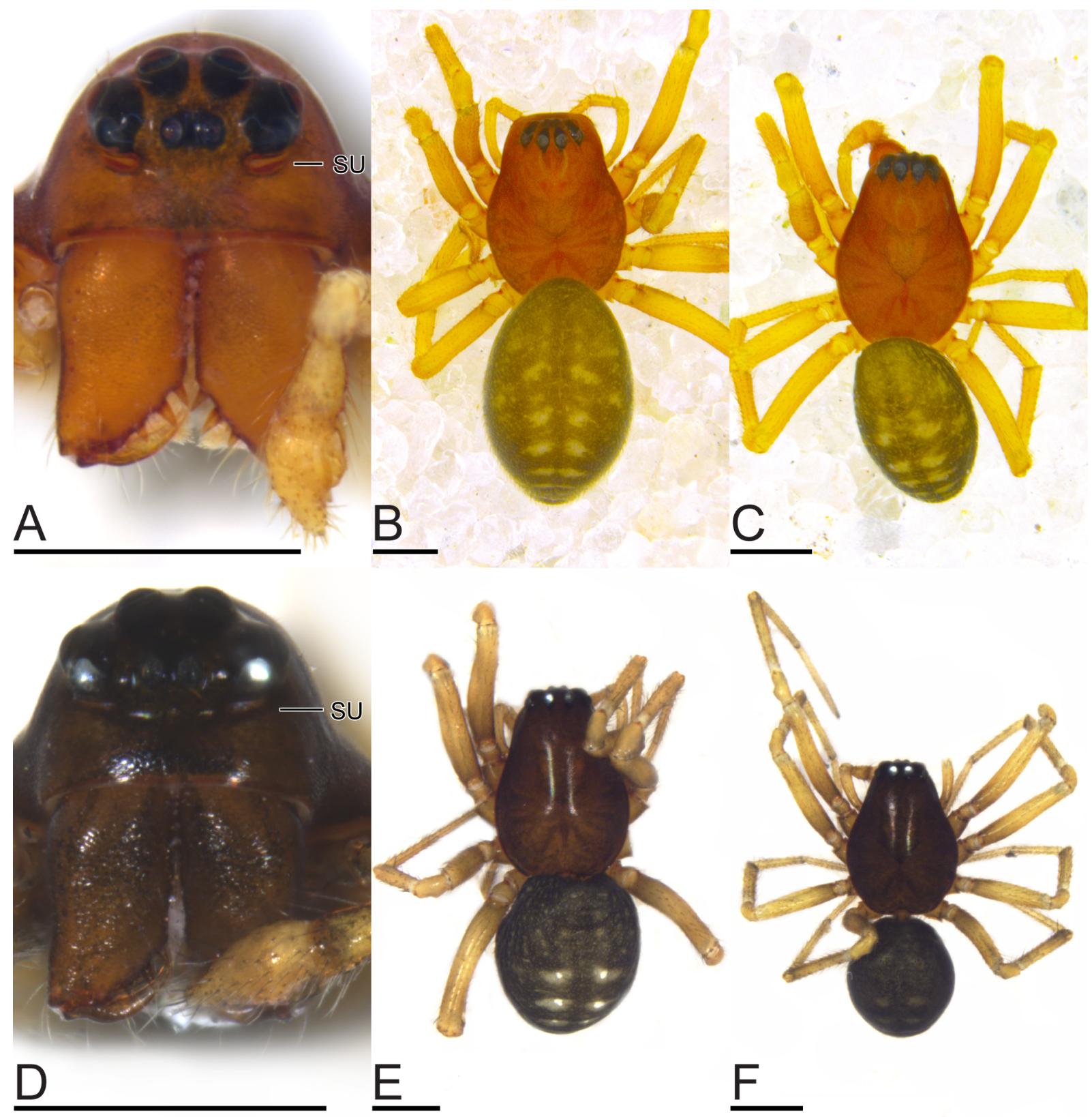

Fig. 11. A-C. Afroneta serrata sp. nov. A. Holotype, đ̊ (UPSZMC 67569), habitus, frontal. B. Allotype, q (UPSZMC 67569), habitus, dorsal. C. ô (UPSZMC 67570), habitus, dorsal. - D-F. Afroneta sarahae sp. nov. D. Holotype, ô (ZMUN 24056), habitus, frontal. E. Allotype, o (ZMUN 24056), habitus, dorsal. F. Holotype, $\widehat{\jmath}$ (ZMUN 24056), habitus, dorsal. Scale bars: $500 \mu \mathrm{m}$. 
(Figs 9A-B, 10A-B). Radix drop-like. Embolus with broad base, robust and almost straight and tapering towards the tip (Figs 9C, 10C). Embolic membrane exceeding the embolus and the alveolus (Fig. 9C).

Female (allotype, UPSZMC 67569)

SizE. Total length 3.03. Cephalothorax 1.45 long, 1.07 wide. Sternum 0.84 long ( 0.75 without labium), 0.67 wide. Abdomen 1.79 long, 1.17 wide. AME diameter 0.05. Femur I 0.94 long, 1.54 times as long as cephalothorax.

Colour (preserved specimen, Fig. 11B). As holotype.

BoDy. Sternum shield-shaped. Clypeus height 4.6 times AME diameter.

Chelicerae. With 3 large widely spaced prolateral teeth. Retrolateral denticles not visible. Chelicerae without stridulating file.

LEGS. Spination of legs like male. Leg formula 1243. Trichobothrium metatarsus I $=0.44$.

Epigynum And vulva (Figs 9D-E, 10E-F). The epigyne has a dorsal plate scape that is moderately developed and neither extends much ventrally nor posteriorly (Fig. 10E-F). The copulatory ducts exceed beyond the receptacula anteriorly and are seperated from each other by less than their diameter (Fig. 10G-H). The receptacula are round.

\title{
Distribution
}

Only know from Mount Elgon, Kenya, at altitudes between 3980 and 4200 m a.s.l.

\section{Life history}

Little is known about the biology of this species. Specimens have been collected in the alpine belt above the forest zone. According to Holm it was taken from moss and grass on the ground in an area with Senecio L.

\author{
Afroneta sarahae sp. nov. \\ urn:1sid:zoobank.org:act:ACC8A04A-41EE-489B-B929-3912135333E2
}

Figs 11D-F, 12-13

\section{Diagnosis}

The presence of serrations on the ventral margin of the paracymbium is seen in only one more species, Afroneta serrata sp. nov. The shape of the serrations is variable (see Fig. 13B-E), ranging from many shallow fine denticles to a few deep strong teeth. The tegular mynoglenine process is roundish and smaller compared to what is seen in Afroneta serrata sp. nov. The radix is situated in the distal half of the cymbium (Fig. 13F) and is shorter than in Afroneta serrata sp. nov. (Fig. 9C). The copulatory duct in females is correspondingly shorter (Fig. 12G-H) than in Afroneta serrata sp. nov. (Fig. 10G-H) and the dorsal plate with the dorsal plate scape is also narrower in its longitudinal dimension (Fig. 9D vs Fig. 13G).

\section{Etymology}

The species epithet sarahae is a name in apposition. It refers to Holger Frick's partner, Sarah Küffer, who has supported Holger Frick's passion for spiders for more than a decade. 


\section{Type material}

\section{Holotype}

KENYA: $\hat{\alpha}^{1}$, Rift Valley Prov., Trans-Nzoia Distr., Mount Elgon National Park, upper course of Kimothon Riv., 15'53.1" N, 34³7'13.7" E [WGS84], 3645 m a.s.1., 19 Jan. 2009, N. Yunakov leg., H. Frick det., collection Natural History Museum of Oslo (sample KE005, ZMUN 24056).

\section{Allotype}

KENYA: , same data as for holotype (ZMUN 24056).

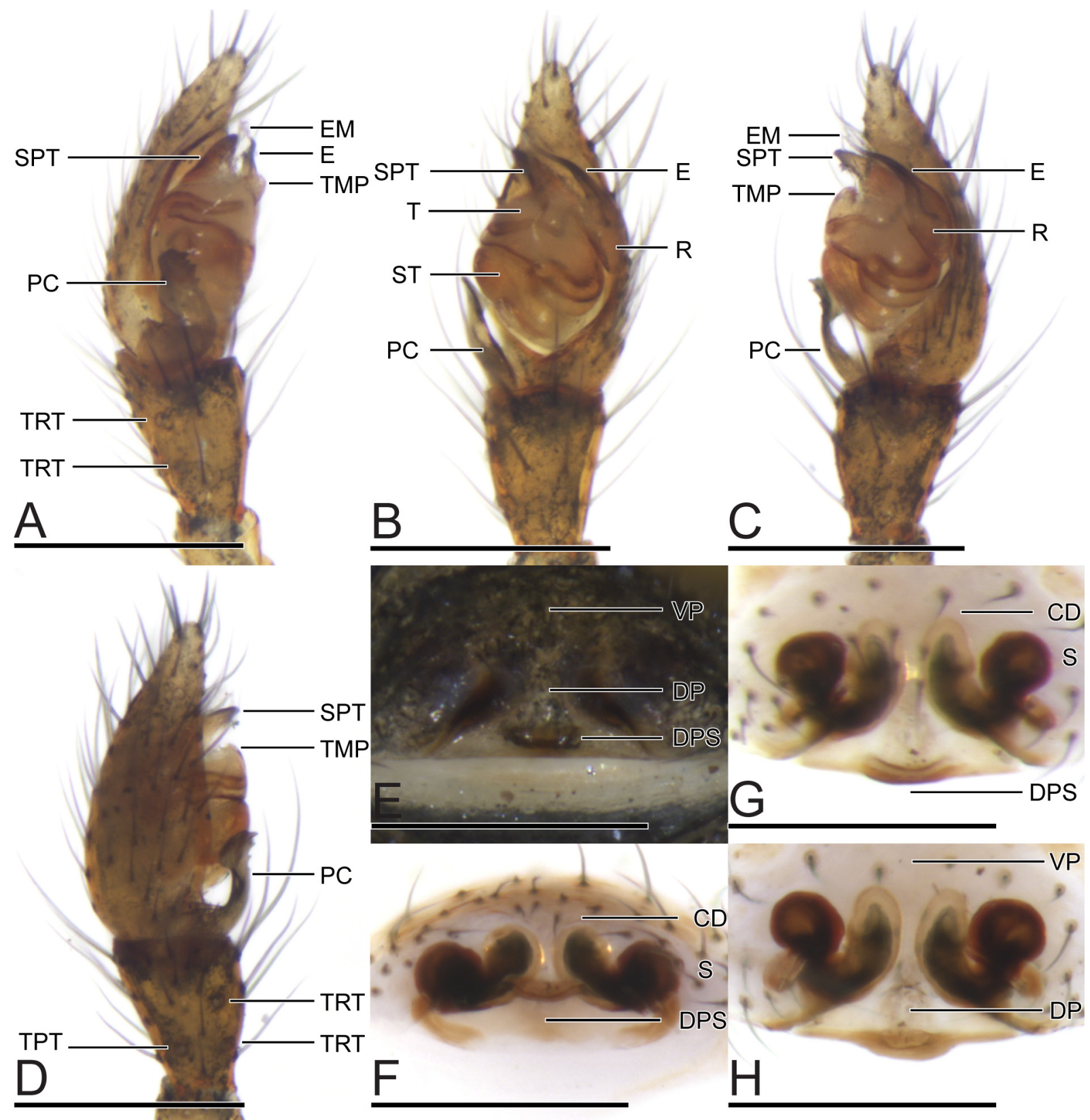

Fig. 12. Afroneta sarahae sp. nov. A-D. Holotype, $\widehat{\partial}$ (ZMUN 24056). A. Palp, retrolateral. B. Ventral. C. Prolateral. D. Dorsal. E-H. Allotype, q (ZMUN 24056). E. Epigyne, ventral. F. Cleared vulva, aboral. G. Ventral. H. Dorsal. Scale bars: $200 \mu \mathrm{m}$. 
Other material examined $(1 \hat{\partial}, 7$ $\rho$ $\rho)$

KENYA: 1 $\delta, 7$ 우, together with holotype, collection Natural History Museum of Oslo (sample KE005, ZMUN 24056).

\section{Description}

Male (holotype, ZMUN 24056)

SizE. Total length 1.88. Cephalothorax 1.06 long, 0.76 wide. Sternum 0.59 long ( 0.54 without labium), 0.53 wide. Abdomen 0.91 long, 0.72 wide. AME diameter 0.04 . Femur I 0.79 long, 0.75 times as long as cephalothorax.

Colour (preserved specimens, Fig. 11D, F). Cephalothorax and chelicerae brownish, sternum darker and with blackish-grey margin. Legs and pedipalps yellowish white, without annulations. Black rings around eyes. Abdomen dark grey, with white markings. Figure 11D-F illustrates recently collected material (2009), stored in $96 \%$ ethanol. The colour is probably close to the colour of the live animals.

Body. Cephalothorax with short pale setae in the midline. No fovea (Fig. 11F). Ocular area without setae between eyes. Clypeus height 4 times AME diameter. Subocular sulci present below ALE, clearly demarcated, longer than wide and narrow (Fig. 11D). Cephalothorax more elongated and narrower (Fig. 11E-F) as compared to Afroneta serrata sp. nov. (Fig. 11B-C).

Chelicerae. With 3 large widely spaced prolateral teeth (Fig. 11D). Without stridulating file. Three small closely spaced retrolateral denticles, positioned between the two first prolateral teeth.

LeGs. All femora with short thin setae dorsally and ventrally. Ventral setae shorter than diameter of femora. Leg formula 1243. Trichobothrium metatarsus $\mathrm{I}=0.37$ ( 0.41 on other male specimen in vial). No tibial spines.

Pedipalp (Figs 12A-D, 13A-F). Patella with long strong macrosetae (Fig. 12A). Tibia with two retrolateral and one prolateral trichobothrium (Fig. 12D). Cymbium with two prolateral macrosetae (Fig. 13A). Paracymbium J-shaped, with unusual distal serrations on ventral margin (Fig. 13A-F). It holds two basal setae (Fig. 13A) and its distal part is well set off from the cymbium in dorsal view (Fig. 12D). Suprategulum narrow and triangular. Tegular mynoglenine process short and roundish (Figs 12A, 13A), smaller than in Afroneta serrata sp. nov. (Figs 9A, 10A). Radical division small restricted to distal half of alveolus (Fig. 13F). Radix drop-like. Embolus with broad base, robust and almost straight and tapering towards the tip (Figs 12C, 13C). Embolic membrane exceeding the embolus and the alveolus only slightly (Fig. 13F), less than in Afroneta serrata sp. nov.

Female (allotype, ZMUN 24056)

SizE. Total length 2.41 (abdomen strongly bent downwards so total length difficult to measure). Cephalothorax 1.44 long, 0.96 wide. Sternum 0.79 long ( 0.71 without labium), 0.63 wide. Abdomen 1.32 long, 0.91 wide. AME diameter 0.06. Femur I 1.00 long, 0.71 times as long as cephalothorax.

Colour (preserved specimen, Fig. 11E). As holotype.

BoDy. Sternum shield-shaped. Clypeus height 3.5 times AME diameter.

Chelicerae. With 3 large widely spaced prolateral teeth. Retrolateral denticles not visible. Chelicerae without stridulating file.

Legs. Spination of legs like male. Leg formula 1243. Trichobothrium metatarsus I $=0.47$. 
Epigynum and vulva (Figs 12E-H, 13G-H). The epigyne has a dorsal plate scape that is moderately developed and neither extends much ventrally nor posteriorly (Fig. 12E-F). The copulatory ducts expand anteriorly as far as the receptacula and are separated from each other by less than their diameter (Fig. 12G-H). The receptacula are round.

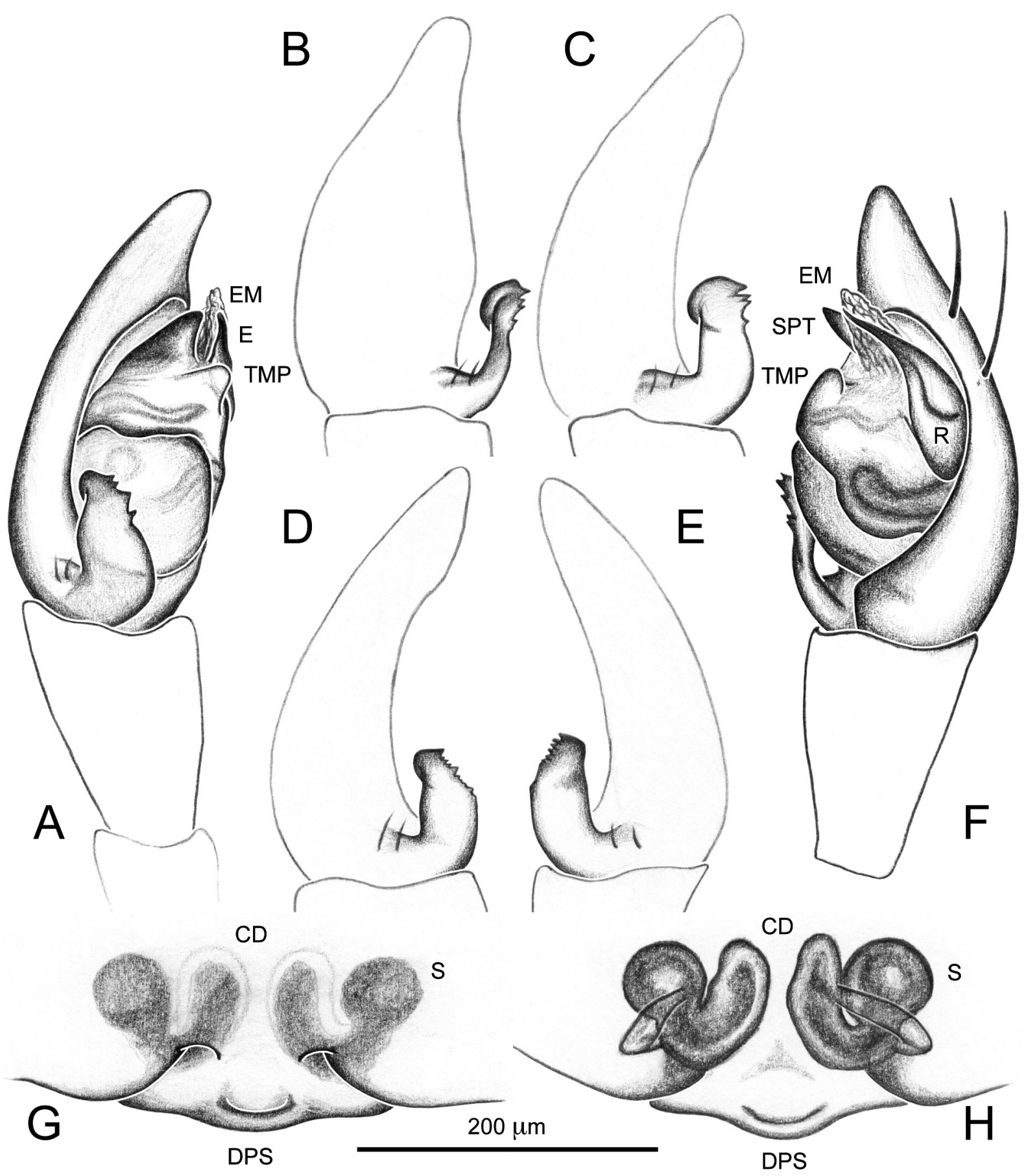

Fig. 13. Afroneta sarahae sp. nov. A-F. Holotype, $\widehat{\partial}$ (ZMUN 24056). A. Palp, retrolateral. B. Paracymbium different angle, retrolateral. C. Palp, paracymbium different angle, retrolateral. D. Right palp specimen 2, paracymbium, retrolateral. E. Left palp specimen 2, paracymbium, retrolateral. F. Palp, prolateral. G-H. Allotype, o (ZMUN 24056). G. Epigyne, ventral. H. Vulva, dorsal. Scale bar: $200 \mu \mathrm{m}$. 


\section{Distribution}

Only know from Mount Elgon, Kenya, at altitudes of 3700 m a.s.1.

\section{Life history}

Little is known about the biology of this species. Specimens have been collected in the alpine belt above the forest zone.

\section{Discussion}

According to Blest \& Vink (2002) only eight mynoglenine species were known, when Lehtinen (1967) erected the subfamily Mynogleninae. Based on material from collections, Blest (1979) was able to describe another 64 species from New Zealand. Despite his effort, Blest \& Vink $(2002,2003)$ added another 26 species to the fauna of New Zealand during a study that specifically focussed on New Zealand mynoglenines.

When Holm (1968) described the first African mynoglenine, he also emphasized how little was known about the linyphiid fauna of Africa. Despite considerable subsequent work on African Linyphiidae, this statement is still true, and especially for mynoglenines.

The first ten new mynoglenine species described by Holm (1968) were placed in the new genus Afroneta. All new species were based on material stored at the MRAC in Tervuren, Belgium. Merrett (2004) expanded our knowledge about the African mynoglenines, by describing another 15 new species, and all these species were also based on material from MRAC. At this point, 32 African mynoglenine species were recognized. Only one more species has been described from Africa since 2004. Holm never managed to describe his own material collected during his first expeditions to Africa in 1938 and 1948. This is first done now, in this paper.

Mynoglenines have rather specific life histories in Africa. They presumably prefer wet litter and low vegetation habitats in high elevation areas. Most species have been found above $2000 \mathrm{~m}$ and many at much higher altitudes. No species have been found below $1700 \mathrm{~m}$ on mainland Africa. This is very different from the mynoglenines of New Zealand, where species can be found at sea level. Why mynoglenines are not found at lower altitudes in Africa is unknown, but could be due to a preference for cold climate or competition. The linyphiid fauna of Africa, and especially the high mountains of Africa, is still very poorly investigated, so many more species are expected to be found in the temperate-cold parts of Africa.

The new species Camafroneta oku gen. et sp. nov. is only know from relatively high altitudes in the very isolated montane forests of Mount Oku, Cameroon. It was collected during a trip where Mount Kupe and Mount Cameroon were also sampled, without finding representatives of the new genus. However, we strongly believe that more species of the new genus will turn up when more sampling is carried out in West Africa.

To justify the description of a new monotypic genus at the current state of knowledge we put the phylogenetic position of Camafroneta oku gen. et sp. nov. to a test. Including it in the phylogeny of Frick \& Scharff (2014) showed that it does not emerge within an existing genus and that there is almost no support for a sister relationship to an existing genus (Fig. 14).

This paper also describes three new species of Afroneta. They were all collected on Mount Elgon and clearly show that there is much more to be found in East Africa. Almost all known species of Afroneta have been described from the high mountains of Eastern Africa. The only exception is Afroneta bamilekei from Cameroon. Mynoglenines have a strange worldwide distribution pattern, with 37 species in Africa 
FRICK H. \& SCHARFF N., New mynoglenine spiders from Africa

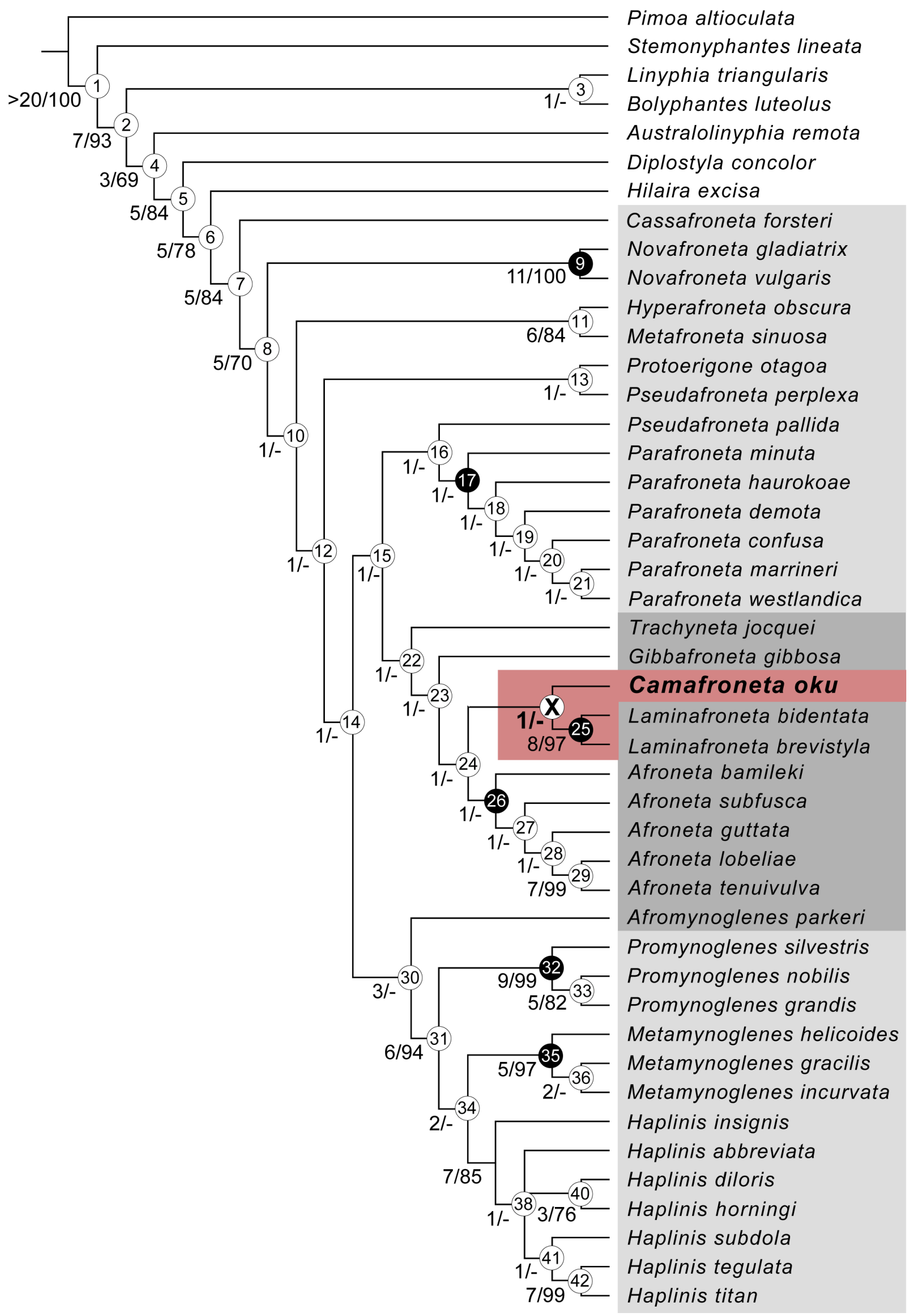

Fig. 14. Phylogeny of Frick \& Scharff (2014) with Camafroneta oku sp. nov. added to the matrix. 
(incl. the island La Réunion, France) and 90 species in New Zealand and the South Pacific islands. Frick \& Scharff (2014) published a phylogeny of the subfamily based on 44 species from the entire distribution range, but with limited representatives of the African clades. Two African genera, Afroneta and Laminafroneta, are more widespread in Africa, whereas the rest of the genera are endemic to smaller geographic areas. A species level phylogeny of the African mynoglenines would be extremely interesting, and would give us a better understanding of the evolutionary history and distribution patterns.

\section{Acknowledgements}

We would like to thank the following people and institutions for making specimens available for examination: Hans Mejlon and Mats Eriksson (Uppsala, Sweden; Evolutionsmuseet, UZM), Rudy Jocqué (Tervuren, Belgium; Musée Royal de l'Afrique Centrale, MRAC), Vladimir Gusarov (Oslo, Norway; Natural History Museum of Oslo, ZMUN) and the Natural History Museum of Denmark (ZMUC). We would also like to thank Torbjörn Kronestedt for help concerning the whereabouts of the original manuscripts of Åke Holm and the two reviewers Marco Isaia and Cor Vink for their valuable comments on the manuscript. The work was made possible by a Synthesys grant DK-TAF 5254 to HF to work at the Natural History Museum of Denmark. HF would also like to thank the Natural History Museum of Bern (Switzerland) for the possibility to use their equipment. NS acknowledge the Danish National Research Foundation for funding for the Center for Macroecology, Evolution and Climate (grant number DNRF96).

\section{References}

Blest A.D. 1979. The spiders of New Zealand. Part V. Linyphiidae-Mynoglenidae. Otago Museum Bulletin 5: 95-173.

Blest A.D. \& Vink C.J. 2002. New Zealand spiders: Linyphiidae, Mynogleninae. Records of the Canterbury Museum 16 (Suppl.): 1-31.

Blest A.D. \& Vink C.J. 2003. New Zealand spiders: Linyphiidae, Mynogleninae, Linyphiinae. Records of the Canterbury Museum 17 (Suppl.): 1-30.

Bosmans R. 1988. Scientific report of the Belgian Cameroon expeditions 1981 and 1983. No. 18. Further Erigoninae and Mynogleninae (Araneae: Linyphiidae) from Cameroonian highlands. Revue zoologique Africaine 102: 5-32.

Frick H. \& Scharff N. 2014. Phantoms of Gondwana? - phylogeny of the spider subfamily Mynogleninae (Araneae: Linyphiidae). Cladistics 30: 67-106. https://doi.org/10.1111/cla.12025

Holm Å. 1962. The Spider Fauna of the East African Mountains. Zoologiska Bidrag från Uppsala 35: $19-204$.

Holm Å. 1968. Spiders of the families Erigonidae and Linyphiidae from East and Central Africa. Annales du Musée Royal de l'Afrique Centrale 171: 1-49.

Holm A. 1979. A taxonomic study of European and East African species of the genera Pelecopsis and Trichopterna (Araneae, Linyphiidae), with descriptions of a new genus and two new species of Pelecopsis from Kenya. Zoologica Scripta 8: 255-278.

Kraus O. 1984. Hoyers Gemisch statt Polyvinyl-Lactophenol. Mikrokosmos 73 (2): 54-55.

Lehtinen P.T. 1967. Classification of the cribellate spiders and some allied families, with notes on the evolution of the suborder Araneomorpha. Annales Zoologici Fennici 4: 199-468.

Merrett P. 2004. A revision of African mynoglenines (Araneae: Linyphiidae: Mynogleninae). Bulletin of the British Arachnological Society 13: 1-30. 
Merrett P. \& Russell-Smith A. 1996. New mynoglenine spiders from Ethiopia (Araneae: Linyphiidae: Mynogleninae). Bulletin of the British Arachnological Society 10: 218-224.

Roberts M.J. 1987. The Spiders of Britain and Northern Ireland. Volume II. Linyphiidae. Harley Books, Colchester, UK.

Wallin L. 1990. Catalogue of Åke Holm 's Collection of Spiders - 3. Tropical Material. Uppsala University Museum Publication, Uppsala. Unpublished report.

Manuscript received: 13 July 2017

Manuscript accepted: 16 October 2017

Published on: 20 March 2018

Topic editor: Rudy Jocqué

Desk editor: Kristiaan Hoedemakers

Printed versions of all papers are also deposited in the libraries of the institutes that are members of the EJT consortium: Muséum national d'Histoire naturelle, Paris, France; Botanic Garden Meise, Belgium; Royal Museum for Central Africa, Tervuren, Belgium; Natural History Museum, London, United Kingdom; Royal Belgian Institute of Natural Sciences, Brussels, Belgium; Natural History Museum of Denmark, Copenhagen, Denmark; Naturalis Biodiversity Center, Leiden, the Netherlands; Museo Nacional de Ciencias Naturales-CSIC, Madrid, Spain; Real Jardín Botánico de Madrid CSIC, Spain. 